\title{
Gastrectomy Alone or in Combination With Hepatic Resection in the Management of Liver Metastases From Gastric Cancer: A Systematic Review Using an Updated and Cumulative Meta-Analysis
}

\author{
Paschalis Gavriilidis ${ }^{\mathrm{a}, \mathrm{b}, \mathrm{d}}$, Keith J. Roberts ${ }^{\mathrm{b}}$, Nicola de'Angelis ${ }^{\mathrm{c}}$, \\ Robert P. Sutcliffe $e^{b}$
}

\begin{abstract}
Background: Recent studies have demonstrated that hepatectomy in patients with synchronous hepatic gastric metastases may improve survival in certain patients. This study aimed to evaluate survival benefits of gastrectomy plus hepatectomy versus gastrectomy alone in patients with hepatic gastric metastases.
\end{abstract}

Methods: Studies were identified by a systematic search of Embase, PubMed, Cochrane Library, and Google Scholar databases. Traditional and cumulative meta-analyses were used to monitor the evidence over time.

Results: Eleven studies which included 861 patients compared gastrectomy plus hepatic resection in 349 patients with gastrectomy alone in 512 patients. Overall significantly better survival rates of $1,2,3$, and 5 years were demonstrated for patients who underwent gastrectomy plus hepatic resection compared to patients who under underwent gastrectomy alone ((hazard ratio $(\mathrm{HR})=0.52(0.39$, $0.69), \mathrm{P}<0.001),(\mathrm{HR}=0.85$ (0.74, 0.97), $\mathrm{P}=0.01),(\mathrm{HR}=0.80$ $(0.72,0.90), \mathrm{P}=0.003),(\mathrm{HR}=0.83(0.78,0.90), \mathrm{P}<0.001)$, respectively).

Conclusions: Carefully selected patients with hepatic gastric metastases may benefit from hepatic resection.

Keywords: Hepatic metastases; Gastric adenocarcinoma; Hepatec-

Manuscript submitted July 6, 2019, accepted July 18, 2019

a Department of Hepato-Biliary-Pancreatic and Oesophago-Gastric Surgery, Imperial College Healthcare NHS Trust, Hammersmith Hospital, London W12 0HS, UK

${ }^{b}$ Department of Hepato-Pancreato-Biliary and Liver Transplant Surgery, Queen Elizabeth University Hospitals Birmingham, NHS Foundation Trust, B15 2TH, UK

'Department of Digestive Surgery, Henri Mondor University Hospital, Creteil 94010, France

${ }^{\mathrm{d} C o r r e s p o n d i n g ~ A u t h o r: ~ P a s c h a l i s ~ G a v r i i l i d i s, ~ I m p e r i a l ~ C o l l e g e ~ H e a l t h c a r e ~}$ NHS Trust, Hammersmith Hospital, London W12 0HS, UK. Email: pgavrielidis@yahoo.com

doi: https://doi.org/10.14740/jocmr3925 tomy; Gastrectomy

\section{Introduction}

Gastric cancer has a poor prognosis and it is the second most common cause of cancer deaths worldwide [1]. At the time of diagnosis, only $30 \%$ of the patients are suitable for curative treatment [2]. Synchronous hepatic metastases are diagnosed in $3 \%$ to $14 \%$ of the patients $[3,4]$, while metachronous variants appear in $37 \%$ of patients after curative gastrectomy [5]. Current evidence recommends supportive therapy and palliative chemotherapy for patients with peritoneal spread and distant metastases [6]. The results of a randomized phase 3 trial conducted in Japan, South Korea and Singapore compared the survival benefits of gastrectomy followed with chemotherapy against chemotherapy alone in patients with advanced cancer and with a single non-curable factor confined either to the peritoneum, liver, or para-aortic lymph nodes $(16 \mathrm{a} 1 / \mathrm{b} 2)$. The result did not demonstrate any survival benefits from the gastrectomy [7]. Therefore, gastrectomy cannot be justified as a treatment option for that group of patients.

Recent meta-analysis demonstrated survival benefits of hepatic resection in cases of hepatic gastric metastases in carefully selected patients [8].

The aim of the present study is to evaluate the survival benefits of the gastrectomy plus hepatectomy $(\mathrm{GH})$ compared with gastrectomy (GA) alone for cases of hepatic metastases from gastric adenocarcinoma using traditional and cumulative meta-analyses.

\section{Materials and Methods}

This systematic review and meta-analysis was carried out in accordance with the guidelines set out in the Preferred Reporting Items for Systematic Review and Meta-Analysis (PRISMA) checklist [9]. The article does not contain any studies with human or animal subjects performed by any of 
the authors.

\section{Literature search}

A systematic literature search of articles published in the last 30 years was performed using the Embase, MEDLINE (PubMed), Cochrane library, and Google Scholar databases, using free text and MeSH search terms (gastric cancer, gastrectomy, hepatic or liver gastric metastases, hepatectomy or liver resection for gastric metastases, stomach neoplasms). A grey literature search of the clinicaltrials.gov website was also performed. References in the retrieved articles were checked manually and further analyzed. Disagreements between authors were resolved by consensus.

\section{Study selection, inclusion and exclusion criteria}

Cohort or retrospective studies, and case-matched studies that evaluated the results of the patient undergoing any form of liver resection for liver gastric adenocarcinoma, in the absence of peritoneal metastases were included in the study. All reviews, narrative articles, cohort studies with less than 10 patients, extrahepatic metastases, malignancies other than gastric adenocarcinoma with liver metastases, studies with insufficient data regarding survival outcome after liver resection and nonEnglish language publications were excluded.

\section{Data extraction and outcomes}

Two reviewers (PG and KR) independently extracted the following summary data for the included studies: name of authors; number of patients; age; gender; synchronous, metachronous, unilobar, bilobar, solitary and multiple liver metastases; neoadjuvant and adjuvant therapy; morbidity; median follow-up time; median survival; 1-, 2-, 3-, and 5-year overall survival; and 30-day mortality. Primary outcomes were 1-, 2-, 3-, and 5-year overall survival.

\section{Assessment of included studies}

Two authors (PG, KR) independently assessed the quality of evidence provided by each study using the Oxford Center for Evidence-Based Medicine scoring system [10]. Moreover, the methodological qualities of all retrospective comparative studies were assessed with the validated Newcastle-Ottawa Scale (NOS) [11]; studies that scored $\geq 7$ were considered of high quality. NOS is an assessment tool used to measure the quality of retrospective studies included in a systematic review and meta-analysis. Using this tool, each study was assessed using eight parameters, categorized into three groups: first, the selection of the study groups; second, the comparability of the groups; and third, the ascertainment of either the exposure or outcome of interest for case-control studies, respectively. One point was awarded for each quality item. The highest quality studies were awarded up to nine points [11].

\section{Statistical analysis}

Statistical analysis was conducted using Review Manager 5.3 software (Cochrane Collaboration, Oxford, England). Heterogeneity was assessed through the $\mathrm{I}^{2}$ statistic and cut-off values of $25 \%, 50 \%$, and $75 \%$ were considered low, moderate, and high, respectively [12]. In such cases, both fixed- and randomeffects models were produced, and the conclusions compared, with the latter used preferentially in cases where there were discrepancies between the two models. In cases of $\mathrm{I}^{2}$ values less than $25 \%$, fixed-effects models were used throughout.

Dichotomous variables were analyzed based on odds ratios (ORs) with 95\% confidence intervals (CIs). For the analyzed outcomes, the reference categories were selected so that OR $<$ 1 favored hepatectomy. Continuous variables were combined based on both the mean difference (MD) and the standardized mean difference (SMD). For studies that did not report the mean and variance for the two groups, these values were estimated from the median, range, and the size of sample where possible, using the technique described by Hozo et al [13].

Analysis of long-term survival was performed by combining the hazard ratios (HRs) and 95\% CIs from the included studies. These were rarely reported, and so were estimated using the method described by Parmar et al [14], where this was possible. Studies that reported the numbers at risk were combined with either the quoted survival rates or values read from enlarged plots of the Kaplan-Meier curves to produce the estimates. Where numbers at risk were not quoted, constant censoring over the period of follow-up was assumed in the estimation. The studies were weighted using an inverse variance approach and HRs $<1$ favored the hepatectomy plus gastrectomy approach.

In all analyses, the significance level was set at $\mathrm{P}<0.05$. Cumulative meta-analysis was conducted using STATA software (version 15, Stata Corp LP, TX, USA).

\section{Sensitivity analysis}

Analyses of outcomes were conducted using both randomeffects and fixed-effects models in order to assess the impact of heterogeneity on the results. Moreover, subgroup analyses of the eastern and western studies were performed. Publication bias was not estimated because less than 10 studies were included in each outcome [15]. Cumulative meta-analysis was performed to detect the accumulation of evidence over time.

\section{Results}

\section{Search strategy and included study characteristics}

Forty-three studies, which included 1,198 patients, who underwent hepatic resection for hepatic metastases from gastric adenocarcinoma, were selected from a pool of 1,329 studies (Fig. 1) $[3,4,22,16-55]$. Of these 43 studies, 11 studies comprised 


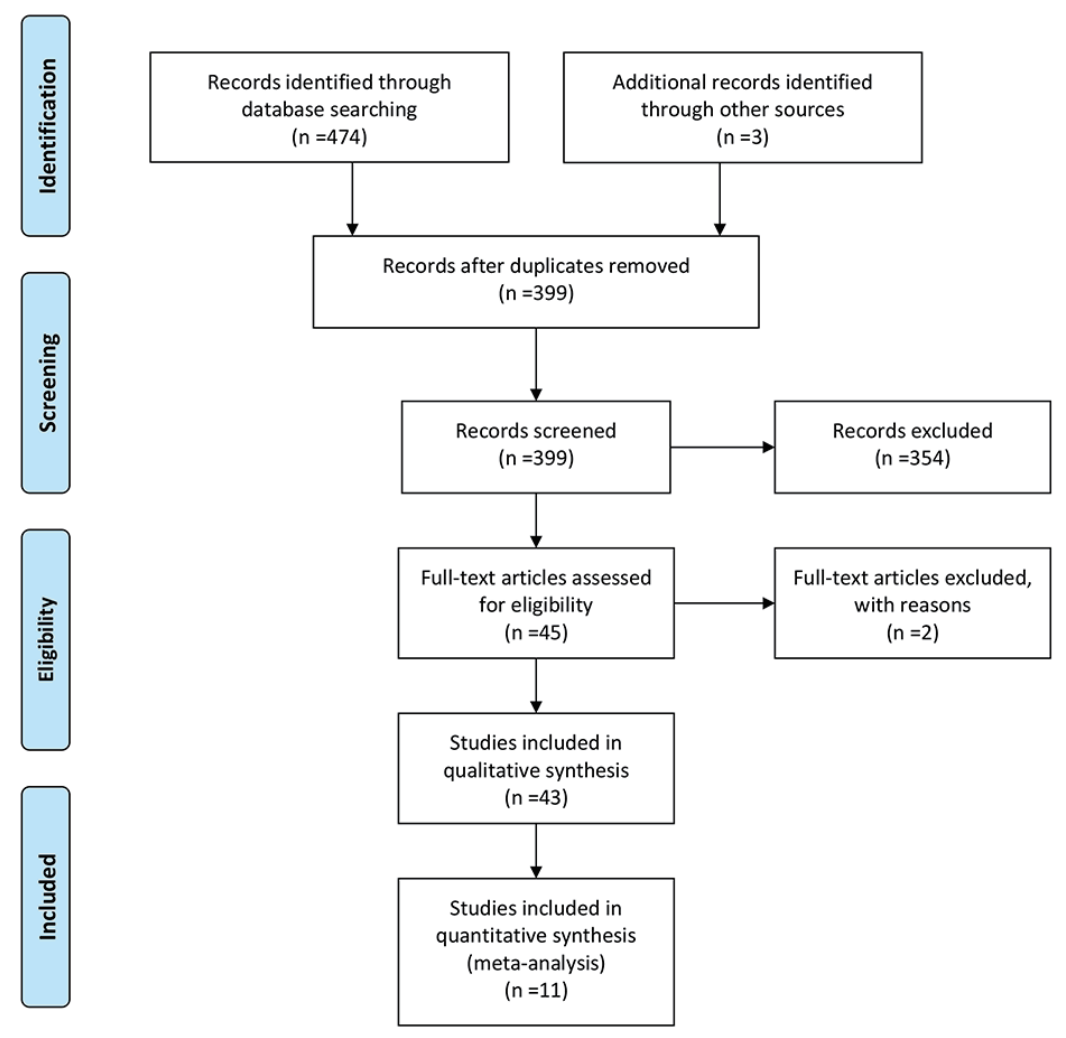

From: Moher D, Liberati A, Tetzlaff J, Altman DG, The PRISMA Group (2009). Preferred Reporting ftems for Systematic Reviews and MetaAnalyses: The PRISMA Statement. PLoS Med 6(7): e1000097. doi:10.1371/journal.pmed1000097

Figure 1. Flow diagram of the search strategy.

of 861 patients compared gastrectomy plus hepatic resection (349 patients) to gastrectomy without hepatic resection (512 patients). Two studies were excluded because of incomplete reporting of outcomes.

The quality of evidence of all 43 studies were assessed as type $2 \mathrm{~b}$ using the Oxford Center for Evidence-Based Medicine scoring system.

All 11 studies comparing gastrectomy plus hepatic resection to gastrectomy alone scored more than seven stars in the NOS and were therefore characterized as being of high quality (Supplementary Table 1, www.jocmr.org).

\section{Results of the 43 studies included in qualitative synthesis}

The median age of the 1,198 patients who underwent hepatic resection was $64(25$ - 89), the majority of whom were men $752(63 \%)$. Eight percent $(8 \%)$ of the patients in these various studies underwent neoadjuvant chemotherapy, whereas $48 \%$ of them underwent adjuvant chemotherapy. Six hundred and seven $(62 \%)$ patients underwent resection for synchronous metastases and $376(38 \%)$ for metachronous metastases. Unilateral metastases occurred in $525(74 \%)$ patients and 188 (26\%) pa- tients have bilateral metastases. Five hundred and forty $(59 \%)$ patients underwent resection for solitary tumors and 377 (41\%) for multiple tumors. Minor hepatectomies were performed in $74 \%$ of patients. Morbidity was $26 \%$ (with a range of $0 \%$ to $60 \%)$ and the 30 -day mortality was $0(0 \%$ to $30 \%)$.

The median 1, 2, 3, 5-year survival was 68\%, 29.5\%, 32\% and $27 \%$, respectively with a median survival of $21(9-52)$ months.

\section{Cumulative meta-analysis}

Cumulative meta-analysis demonstrated that there were no studies which indicate the particular impact on the results over time. In the dichotomous variables of synchronous/metachronous and solitary/multiple metastases, turning points on the accumulation of evidence over time were identified. Particularly, in the synchronous/metachronous forest plot, two time periods were depicted. One ranged from 1994 to 2014 when nonsignificant differences were demonstrated and a second period starting from the study of Sinohara et al in 2015 [52] until present when it was demonstrated that significantly less metachronous metastases compared to synchronous cases were 


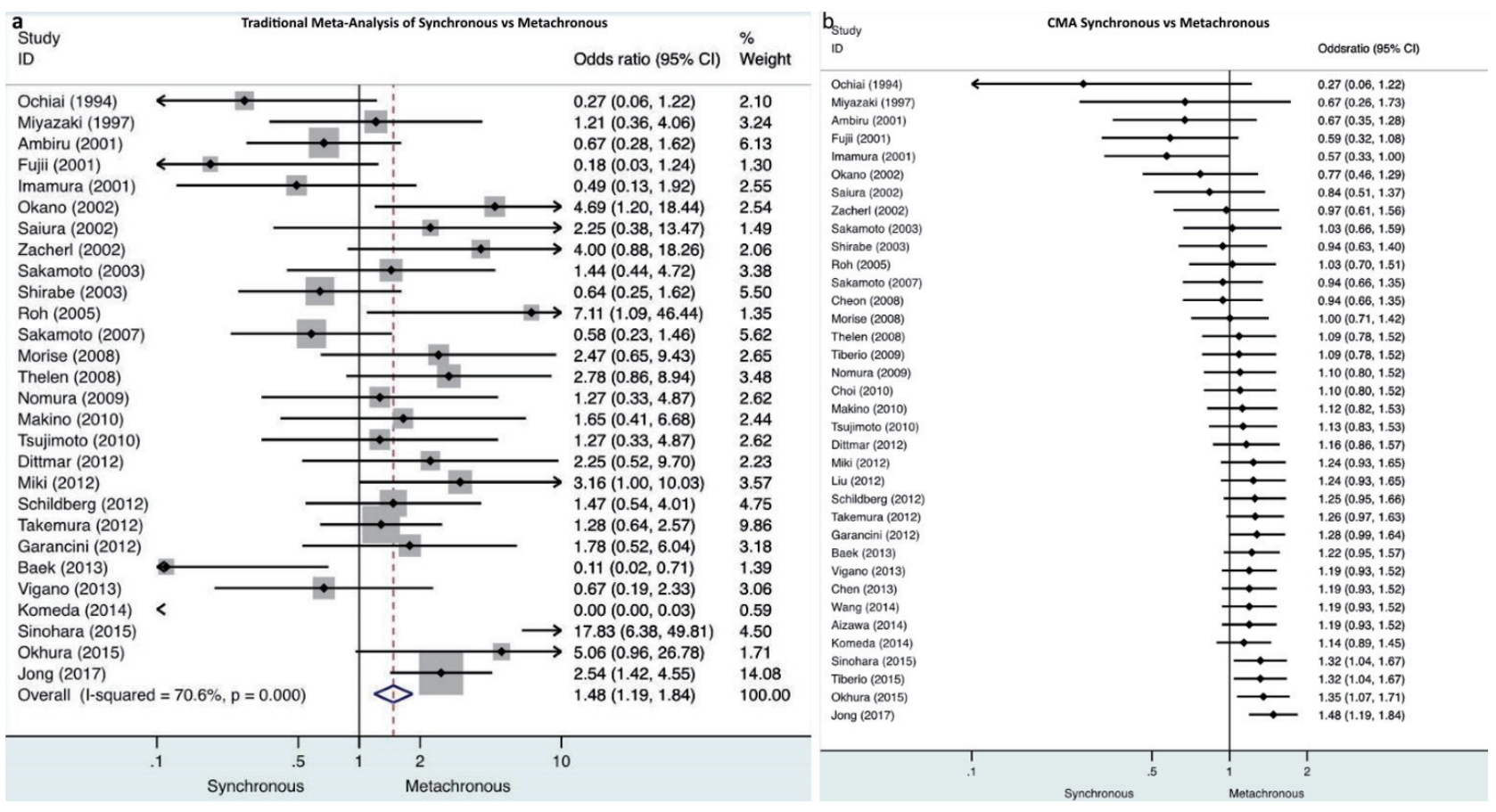

Figure 2. a) Traditional meta-analysis of synchronous/metachronous metastases demonstrates that significantly less metachronous metastases were included compared to synchronous metastases. b) Cumulative meta-analysis of synchronous/metachronous metastases depicts two time periods, one from 1994 to 2014 when nonsignificant differences were demonstrated and a second from 2015 until present when it was demonstrated that significantly less metachronous metastases compared to synchronous cases were included.

included (Fig. 2). Similarly, the time period between 1994 and 2003 is depicted by solitary/multiple forest plots when demonstrably nonsignificant differences exists between solitary and multiple metastases in the included studies. A second period starting in 2003 with the study of Shirabe et al [24] and lasting until present time, demonstrates that significantly less multiple metastases compared to solitary ones were included (Fig. 3).

\section{Meta-analysis of studies comparing GH against GA}

\section{Tumor characteristics}

There were no significant differences in the proportion of synchronous metastases between the GH and GA groups. Similarly, there were no significant differences in the proportion of metachronous metastases between GH (28\%) versus GA (29\%) groups. The proportion of patients with unilobar distribution was significantly higher in the GH (58\%) than in the GA $(25 \%)$ groups. There was no significant difference in the proportion of solitary metastases between the GH cohort and GA cohort (Table 1).

\section{Primary outcomes 1-, 2-, 3-, and 5-year overall survival}

Patient survival for 1-, 2-, 3-, and 5-year was found to be significantly better in GH cohort compared to the GA group (Ta- ble 1) (Fig. 4).

\section{Discussion}

This updated traditional and cumulative meta-analysis consists of 43 studies which included 1,198 patients with a median age of $64(25$ - 89) years, the majority of whom were men accounting for $63 \%$, compared to $27 \%$ who were women. Synchronous metastases cases were $62 \%$ and metachronous cases $38 \%$. Unilobar cases were $74 \%$ and bilobar $26 \%$. Patients with solitary lesions were $59 \%$ while those with multiple lesions were $41 \%$. The 30 -day overall mortality was $0 \%(0-30 \%)$ and the median survival period was 21 (9 - 52) months. The 1-, 2 -, 3-, and 5-year overall survival was 68\% (39-96\%), 29.5\% (25-50\%), 32\% (14-70\%), and 27\% (9-60\%), respectively. The updated results of the present study did not show any significant difference when compared with the results of the previous meta-analysis [8].

Interestingly, CMA depicted turning points in the accumulation of evidence over time. The traditional meta-analysis demonstrated that significantly less metachronous metastases were included in the studies; on the contrary the CMA reveals that its effect size was nonsignificant for the period from 1994 to 2014 , the second period starts in 2015 until present day and it demonstrates that significantly more synchronous metastases were included compared to metachronous. Similarly, discrepancies between the traditional and CMA were demonstrated in the evaluation of solitary/multiple metastases (Figs. 2, 3). The 


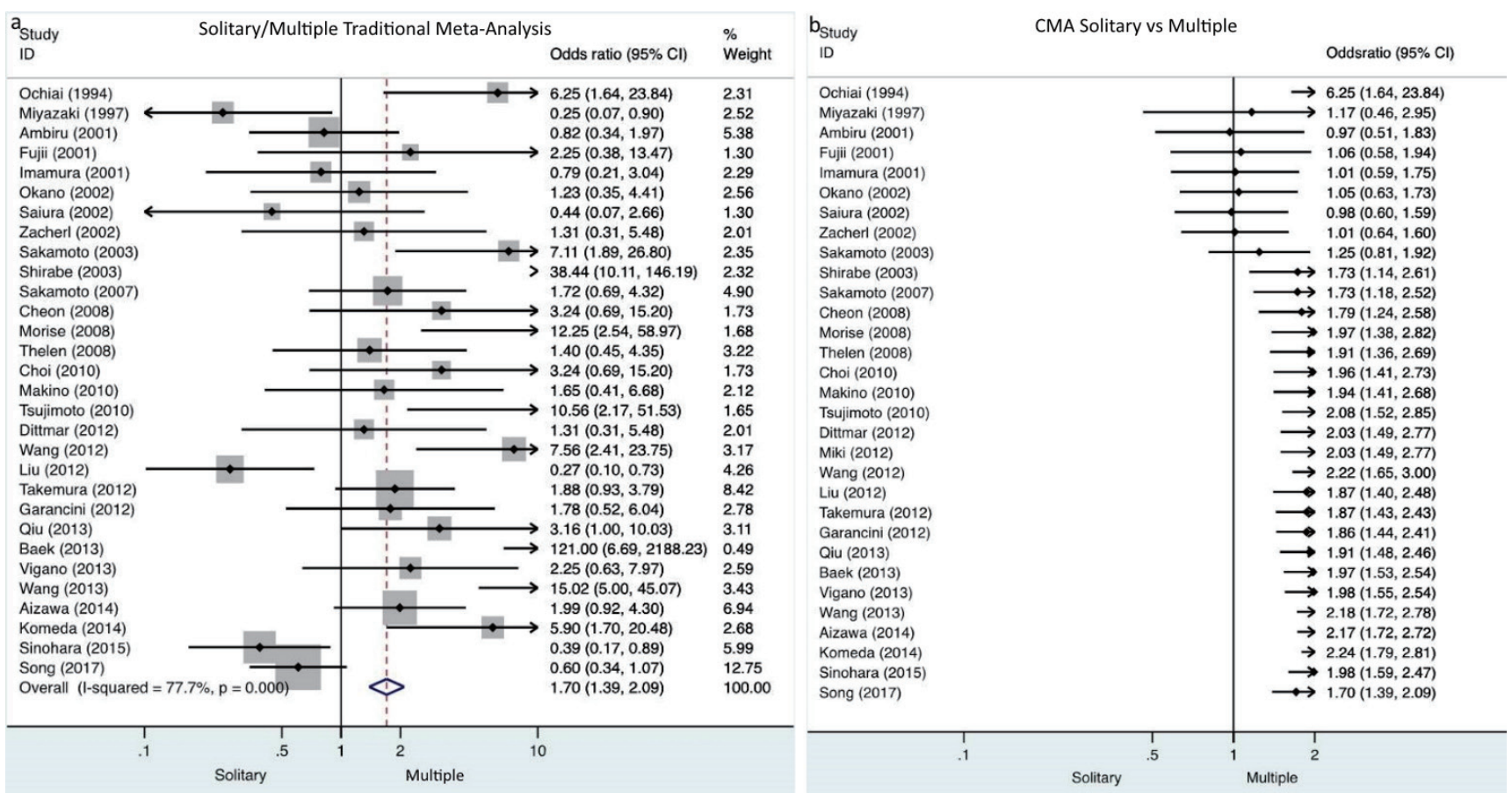

Figure 3. a) Traditional meta-analysis of solitary/multiple metastases demonstrates that significantly less multiple metastases were included compared to solitary metastases. b) Cumulative meta-analysis of solitary/multiple metastases depicts two time periods, one from 1994 to 2003 when nonsignificant differences were demonstrated and a second from 2003 until present when it was demonstrated that significantly less multiple metastases compared to solitary cases were included.

Table 1. Outcomes of Interest

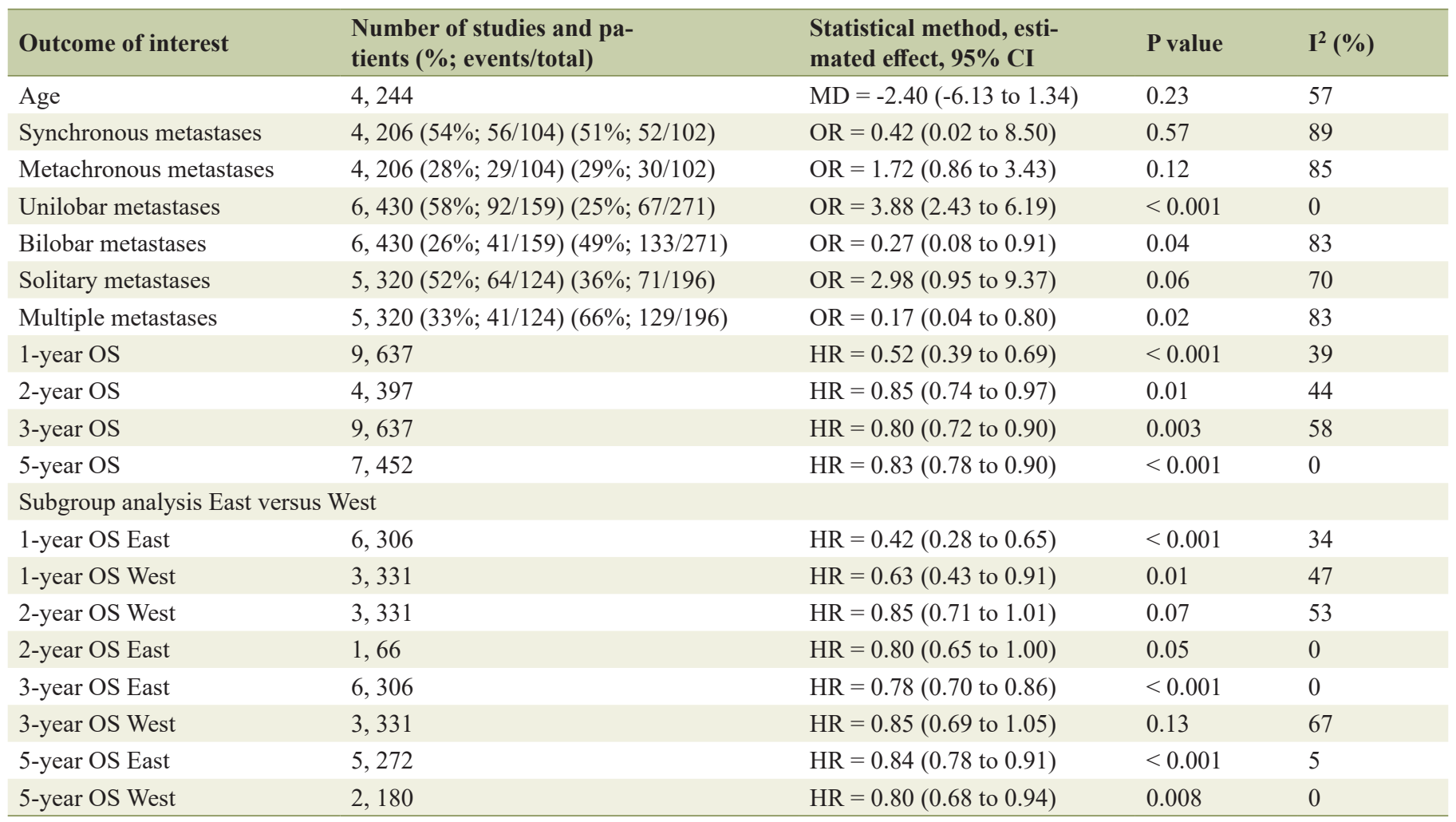

OS: overall survival; MD: mean difference; HR: hazard ratio; OR: odds ratios. 


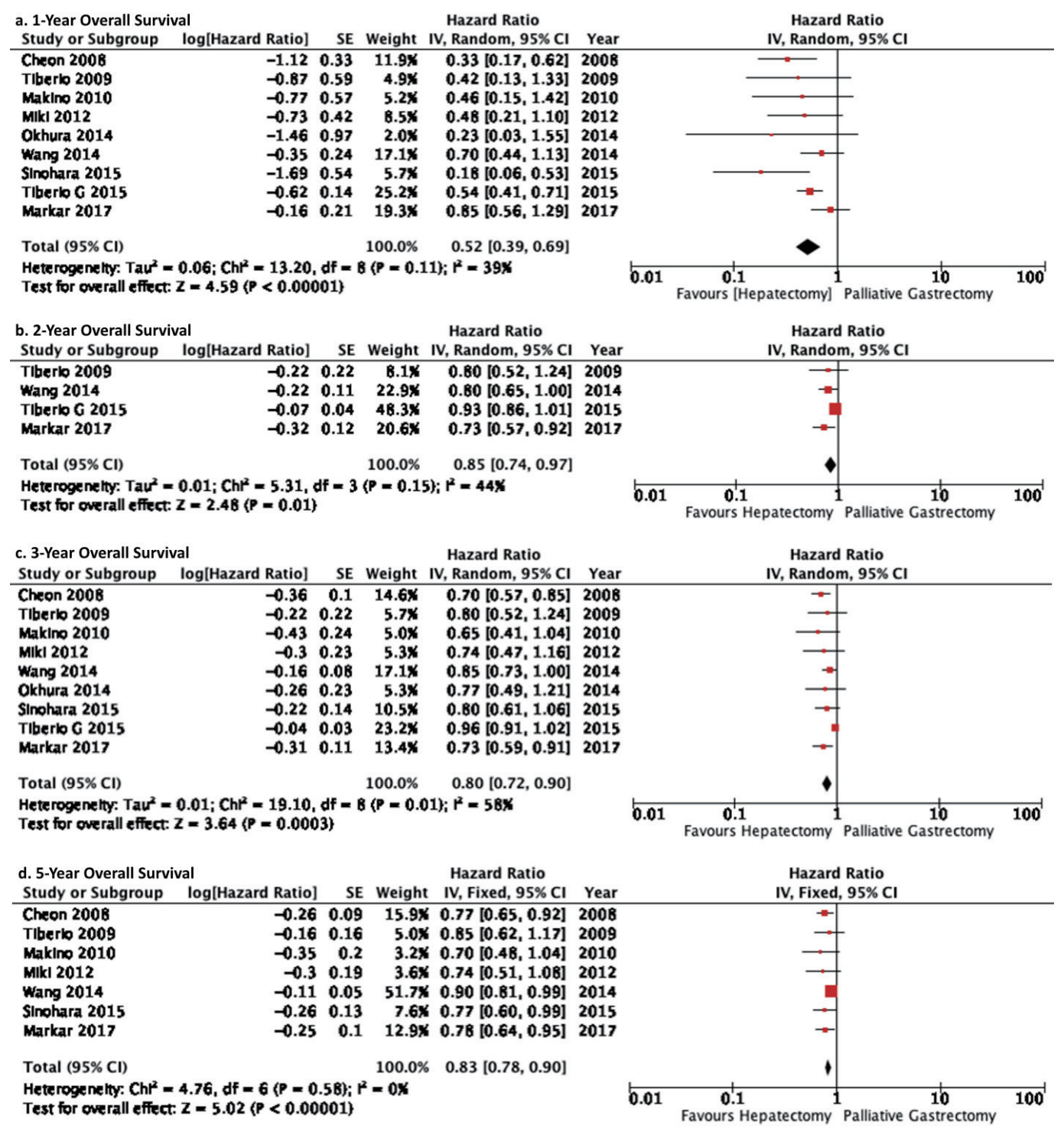

Figure 4. Forest plot depicting 1-, 2-, 3-, 5-year overall survival of gastrectomy plus hepatectomy versus gastrectomy alone. It is depicting that the gastrectomy plus hepatic resection cohort demonstrated significantly better survival benefits compared to gastrectomy alone.

above findings suggest that with the accumulation of evidence and experience, the selection of patients for hepatic resection became more meticulous and careful.

The pair-wise meta-analysis of 11 studies demonstrated that 1-, 2-, 3-, and 5-year overall survival was significantly better in gastrectomy plus hepatectomy cohort compared to gastrectomy alone cohort.

Subgroup analysis demonstrated that there was no evidence of significant difference between Eastern and Western countries in 1-year overall survival (OS); both demonstrated significant results. Interestingly, 2-year OS was marginally nonsignificant in East and West when compared separately. However, this became significant when the two samples were compared together. There was evidence that eastern studies demonstrated significantly better 3-year OS compared to west- ern studies. There were nonsignificant differences in 5-year OS between East and West; both demonstrated significant results (Table 1). Of note, Markar et al [8] evaluated hepatic resections concomitant and non-concomitant with gastrectomy and reported better survival benefits for the East compared to the West. It is apparent that the cohort of patients who underwent gastrectomy with associated hepatic resection were more carefully selected and this is the reason of similar survival benefits between the East and West.

The results of the present study should be interpreted in the context of its limitations. All the studies were retrospective including small numbers of patients carefully selected without extra-hepatic metastases. Therefore, selection, institutional, national bias, underpowered sample size and smaller oncological burden may have influenced the results. Another caveat of 
this study is that very few studies reported detailed morbidity data according to international classifications. Therefore, it was not possible to do meta-analysis of major morbidity.

\section{Conclusions}

The results of this study can justify the adjuvant role of hepatic resection for unilobar gastric liver metastases in carefully selected patients.

\section{Acknowledgments}

None to declare.

\section{Financial Disclosure}

None to declare.

\section{Conflict of Interest}

The authors declare they have no conflict of interest.

\section{Informed Consent}

Not applicable.

\section{Author Contributions}

PG contributed to study concept and design, acquisition of data, analysis and interpretation of data, drafting the manuscript and statistical analysis; KJR was involved in analysis and interpretation of data, and drafting the manuscript; NA contributed to acquisition of data, analysis and interpretation of data, and drafting the manuscript; RPS contributed to acquisition of data, analysis and interpretation of data, drafting the manuscript, and study supervision.

\section{References}

1. Siegel RL, Miller KD, Jemal A. Cancer statistics, 2015. CA Cancer J Clin. 2015;65(1):5-29.

2. National Oesophago-gastric cancer audit-2013, Annual report [Internet]. http://www.hscic.gov.uk/catalogue/ PUB11093 (2013).

3. Saiura A, Umekita N, Inoue S, Maeshiro T, Miyamoto S, Matsui Y, Asakage M, et al. Clinicopathological features and outcome of hepatic resection for liver metastasis from gastric cancer. Hepatogastroenterology. 2002;49(46):1062-1065.

4. Zacherl J, Zacherl M, Scheuba C, Steininger R, Wenzl E, Muhlbacher F, Jakesz R, et al. Analysis of hepatic re- section of metastasis originating from gastric adenocarcinoma. J Gastrointest Surg. 2002;6(5):682-689.

5. D'Angelica M, Gonen M, Brennan MF, Turnbull AD, Bains M, Karpeh MS. Patterns of initial recurrence in completely resected gastric adenocarcinoma. Ann Surg. 2004;240(5):808-816.

6. Ajani JA, Bentrem DJ, Besh S, et al. Esophageal and Esophagogastric junction cancers (excluding the proximal $5 \mathrm{~cm}$ of the stomach) NCCN clinical practice guidelines in oncology (NCCN guidelines). Version 2. 2012;7.

7. Fujitani K, Yang HK, Mizusawa J, Kim YW, Terashima M, Han SU, Iwasaki Y, et al. Gastrectomy plus chemotherapy versus chemotherapy alone for advanced gastric cancer with a single non-curable factor (REGATTA): a phase 3, randomised controlled trial. Lancet Oncol. 2016;17(3):309-318.

8. Markar SR, Mikhail S, Malietzis G, Athanasiou T, Mariette C, Sasako M, Hanna GB. Influence of Surgical Resection of Hepatic Metastases From Gastric Adenocarcinoma on Long-term Survival: Systematic Review and Pooled Analysis. Ann Surg. 2016;263(6):1092-1101.

9. Moher D, Liberati A, Tetzlaff J, Altman DG, The PRISMA Group. Preferred reporting items for systematic reviews and meta-analyses: the PRISMA statement. PLoS Med. 2009;6(7):e1000097.

10. Phillips B, Ball C, Sackett D, et al. Oxford centre for evidence-based medicine-levels of Evidence (March 2009). Available at http://www.cebm.net/oxford-centreevidence-based-medicine-levels-match-2009/.

11. Wells GA, Shea B, O'Connell D, Peterson J, Welch V, Losos M, Tugwell P. The Newcastle-Ottawa scale (NOS) for assessing the quality of nonrandomised studies in meta-analyses. http://www.ohri.ca/programs/clinical_epidemiology/oxford.asp.

12. Higgins JP, Thompson SG, Deeks JJ, Altman DG. Measuring inconsistency in meta-analyses. BMJ. 2003;327(7414):557-560.

13. Hozo SP, Djulbegovic B, Hozo I. Estimating the mean and variance from the median, range, and the size of a sample. BMC Med Res Methodol. 2005;5:13.

14. Parmar MK, Torri V, Stewart L. Extracting summary statistics to perform meta-analyses of the published literature for survival endpoints. Stat Med. 1998;17(24):28152834.

15. Harbord RM, Harris RJ, Sterne JA. Updated tests for small-study effects in meta-analyses. The Stata Journal. 2009;9:197-210.

16. Ochiai T, Sasako M, Mizuno S, Kinoshita T, Takayama T, Kosuge T, Yamazaki S, et al. Hepatic resection for metastatic tumours from gastric cancer: analysis of prognostic factors. Br J Surg. 1994;81(8):1175-1178.

17. Saito A, Korenaga D, Sakaguchi Y, Ohno S, Ichiyoshi Y, Sugimachi K. Surgical treatment for gastric carcinomas with concomitant hepatic metastasis. Hepatogastroenterology. 1996;43(9):560-564.

18. Miyazaki M, Itoh H, Nakagawa K, Ambiru S, Shimizu H, Togawa A, Shiobara M, et al. Hepatic resection of liver metastases from gastric carcinoma. Am J Gastroenterol. 1997;92(3):490-493. 
19. Ambiru S, Miyazaki M, Ito H, Nakagawa K, Shimizu H, Yoshidome H, Shimizu Y, et al. Benefits and limits of hepatic resection for gastric metastases. Am J Surg. 2001;181(3):279-283.

20. Fujii K, Fujioka S, Kato K, Machiki Y, Kutsuna Y, Ishikawa A, Takamizawa J, et al. Resection of liver metastasis from gastric adenocarcinoma. Hepatogastroenterology. 2001;48(38):368-371.

21. Imamura H, Matsuyama $Y$, Shimada R, Kubota M, Nakayama A, Kobayashi A, Kitamura H, et al. A study of factors influencing prognosis after resection of hepatic metastases from colorectal and gastric carcinoma. Am J Gastroenterol. 2001;96(11):3178-3184.

22. Qiu JL, Deng MG, Li W, Zou RH, Li BK, Zheng Y, Lao XM, et al. Hepatic resection for synchronous hepatic metastasis from gastric cancer. Eur J Surg Oncol. 2013;39(7):694-700.

23. Sakamoto Y, Ohyama S, Yamamoto J, Yamada K, Seki M, Ohta K, Kokudo N, et al. Surgical resection of liver metastases of gastric cancer: an analysis of a 17-year experience with 22 patients. Surgery. 2003;133(5):507-511.

24. Shirabe K, Shimada M, Matsumata T, Higashi H, Yakeishi Y, Wakiyama S, Ikeda Y, et al. Analysis of the prognostic factors for liver metastasis of gastric cancer after hepatic resection: a multi-institutional study of the indications for resection. Hepatogastroenterology. 2003;50(53):15601563.

25. Roh HR, Suh KS, Lee HJ, Yang HK, Choe KJ, Lee KU. Outcome of hepatic resection for metastatic gastric cancer. Am Surg. 2005;71(2):95-99.

26. Hirai I, Kimura W, Fuse A, Isobe H, Hachiya O, Moriya T, Suto K, et al. Surgical management for metastatic liver tumors. Hepatogastroenterology. 2006;53(71):757-763.

27. Adam R, Chiche L, Aloia T, Elias D, Salmon R, Rivoire $\mathrm{M}$, Jaeck D, et al. Hepatic resection for noncolorectal nonendocrine liver metastases: analysis of 1,452 patients and development of a prognostic model. Ann Surg. 2006;244(4):524-535.

28. Sakamoto Y, Sano T, Shimada K, Esaki M, Saka M, Fukagawa T, Katai H, et al. Favorable indications for hepatectomy in patients with liver metastasis from gastric cancer. J Surg Oncol. 2007;95(7):534-539.

29. Cheon SH, Rha SY, Jeung HC, Im CK, Kim SH, Kim HR, Ahn JB, et al. Survival benefit of combined curative resection of the stomach (D2 resection) and liver in gastric cancer patients with liver metastases. Ann Oncol. 2008;19(6):1146-1153.

30. Morise Z, Sugioka A, Hoshimoto S, Kato T, Ikeda M, Uyama I, Horiguchi A, et al. The role of hepatectomy for patients with liver metastases of gastric cancer. Hepatogastroenterology. 2008;55(85):1238-1241.

31. Thelen A, Jonas S, Benckert C, Lopez-Hanninen E, Neumann U, Rudolph B, Schumacher G, et al. Liver resection for metastatic gastric cancer. Eur J Surg Oncol. 2008;34(12):1328-1334.

32. Tiberio GA, Coniglio A, Marchet A, Marrelli D, Giacopuzzi S, Baiocchi L, Roviello F, et al. Metachronous hepatic metastases from gastric carcinoma: a multicentric survey. Eur J Surg Oncol. 2009;35(5):486-491.
33. Ueda K, Iwahashi M, Nakamori M, Nakamura M, Naka $\mathrm{T}$, Ishida K, Ojima T, et al. Analysis of the prognostic factors and evaluation of surgical treatment for synchronous liver metastases from gastric cancer. Langenbecks Arch Surg. 2009;394(4):647-653.

34. Nomura T, Kamio Y, Takasu N, Moriya T, Takeshita A, Mizutani M, Hachiya O, et al. Intrahepatic micrometastases around liver metastases from gastric cancer. J Hepatobiliary Pancreat Surg. 2009;16(4):493-501.

35. Choi SB, Song J, Kang CM, Hyung WJ, Kim KS, Choi JS, Lee WJ, et al. Surgical outcome of metachronous hepatic metastases secondary to gastric cancer. Hepatogastroenterology. 2010;57(97):29-34.

36. Makino H, Kunisaki C, Izumisawa Y, Tokuhisa M, Oshima T, Nagano Y, Fujii S, et al. Indication for hepatic resection in the treatment of liver metastasis from gastric cancer. Anticancer Res. 2010;30(6):2367-2376.

37. Tsujimoto H, Ichikura T, Ono S, Sugasawa H, Hiraki S, Sakamoto N, Yaguchi Y, et al. Outcomes for patients following hepatic resection of metastatic tumors from gastric cancer. Hepatol Int. 2010;4(1):406-413.

38. Dittmar Y, Altendorf-Hofmann A, Rauchfuss F, Gotz M, Scheuerlein H, Jandt K, Settmacher U. Resection of liver metastases is beneficial in patients with gastric cancer: report on 15 cases and review of literature. Gastric Cancer. 2012;15(2):131-136.

39. Miki Y, Fujitani K, Hirao M, Kurokawa Y, Mano M, Tsujie M, Miyamoto A, et al. Significance of surgical treatment of liver metastases from gastric cancer. Anticancer Res. 2012;32(2):665-670.

40. Wang YN, Shen KT, Ling JQ, Gao XD, Hou YY, Wang XF, Qin J, et al. Prognostic analysis of combined curative resection of the stomach and liver lesions in 30 gastric cancer patients with synchronous liver metastases. BMC Surg. 2012;12:20.

41. Liu J, Li JH, Zhai RJ, Wei B, Shao MZ, Chen L. Predictive factors improving survival after gastric and hepatic surgical treatment in gastric cancer patients with synchronous liver metastases. Chin Med J (Engl). 2012;125(2):165171.

42. Schildberg CW, Croner R, Merkel S, Schellerer V, Muller $\mathrm{V}$, Yedibela S, Hohenberger W, et al. Outcome of operative therapy of hepatic metastatic stomach carcinoma: a retrospective analysis. World J Surg. 2012;36(4):872878.

43. Takemura N, Saiura A, Koga R, Arita J, Yoshioka R, Ono Y, Hiki N, et al. Long-term outcomes after surgical resection for gastric cancer liver metastasis: an analysis of 64 macroscopically complete resections. Langenbecks Arch Surg. 2012;397(6):951-957.

44. Garancini M, Uggeri F, Degrate L, Nespoli L, Gianotti L, Nespoli A, Uggeri F, et al. Surgical treatment of liver metastases of gastric cancer: is local treatment in a systemic disease worthwhile? HPB (Oxford). 2012;14(3):209-215.

45. Baek HU, Kim SB, Cho EH, Jin SH, Yu HJ, Lee JI, Bang $\mathrm{HY}$, et al. Hepatic resection for hepatic metastases from gastric adenocarcinoma. J Gastric Cancer. 2013;13(2):8692.

46. Vigano L, Vellone M, Ferrero A, Giuliante F, Nuzzo G, 
Capussotti L. Liver resection for gastric cancer metastases. Hepatogastroenterology. 2013;60(123):557-562.

47. Chen L, Song MQ, Lin HZ, Hao LH, Jiang XJ, Li ZY, Chen YX. Chemotherapy and resection for gastric cancer with synchronous liver metastases. World J Gastroenterol. 2013;19(13):2097-2103.

48. Wang W, Liang H, Zhang H, Wang X, Xue Q, Zhang R. Prognostic significance of radical surgical treatment for gastric cancer patients with synchronous liver metastases. Med Oncol. 2014;31(11):258.

49. Aizawa M, Nashimoto A, Yabusaki H, Nakagawa S, Matsuki A. Clinical benefit of surgical management for gastric cancer with synchronous liver metastasis. Hepatogastroenterology. 2014;61(133):1439-1445.

50. Komeda K, Hayashi M, Kubo S, Nagano H, Nakai T, Kaibori M, Wada H, et al. High survival in patients operated for small isolated liver metastases from gastric cancer: a multi-institutional study. World J Surg. 2014;38(10):2692-2697.

51. Tiberio GA, Baiocchi GL, Morgagni P, et al. Gastric cancer and synchronous hepatic metastases: is possible to recognize candidates to R0 resection? Ann Surg Oncol. 2015;22:596-598.

52. Shinohara T, Maeda Y, Hamada T, Futakawa N. Survival benefit of surgical treatment for liver metastases from gastric cancer. J Gastrointest Surg. 2015;19(6):10431051.

53. Ohkura Y, Shinohara H, Haruta S, Ueno M, Hashimoto M, Sakai Y, Udagawa H. Hepatectomy offers superior survival compared with non-surgical treatment for $</=3$ metastatic tumors with diameters $<3 \mathrm{~cm}$ from gastric cancer: a retrospective study. World J Surg. 2015;39(11):27572763.

54. Song A, Zhang X, Yu F, Li D, Shao W, Zhou Y. Surgical resection for hepatic metastasis from gastric cancer: a multi- institution study. Oncotarget. 2017;8(41):7114771153.

55. Markar SR, Mackenzie H, Mikhail S, Mughal M, Preston SR, Maynard ND, Faiz O, et al. Surgical resection of hepatic metastases from gastric cancer: outcomes from national series in England. Gastric Cancer. 2017;20(2):379386. 